\title{
Flap Gate Design for Automatic Upstream Canal Water Level Control
}

\author{
By Charles M. Burt, ${ }^{1}$ Member, ASCE, Russdon Angold, ${ }^{2}$ Mike Lehmkuhl, ${ }^{3}$ \\ and Stuart Styles, ${ }^{4}$ Member, ASCE
}

\begin{abstract}
The EXCEL design procedure for a simple hydraulic flap gate for automatic upstream canal water level control is provided. Basic configurations were developed in The Netherlands in the 1920s and have recently been used in Indonesia, the Dominican Republic, and Nigeria. Four irrigation districts in the San Joaquin Valley of California have constructed and installed over 60 properly functioning flap gates. The gates can be installed within $2 \mathrm{~h}$, but require free discharge conditions and in practice are limited to controlling water depths of about $1 \mathrm{~m}$ or less.
\end{abstract}

\section{INTRODUCTION}

The flap gate is a simple hydraulic automatic upstream water level control gate. Its simplicity is derived from ease of construction and maintenance-construction only requires flat plate and tubing fabrication, rather than curved surfaces as for other types of hydraulic automatic gates. The basic design of a flap gate is shown in Fig. 1. If designed properly, it will automatically maintain the upstream water level within a few centimeters. The gate must be installed in a free-flow condition. The proper operation of a flap gate requires that the gateclosing couple around the pivot point be exactly balanced by the gate-opening couple around that point, while maintaining the same upstream water level at all flow rates (e.g., all angles of opening). Fig. 2 illustrates these two couples. The gateclosing couple is formed by the mass of the gate and counterweight, and the gate-opening couple is formed by the pressure of the water against the faceplate.

Most work on flap gates originated in The Netherlands. Vlugter (1940) investigated various configurations such as the Begemann and Doell. Brouwer (1987) summarizes important design principles, including key dimension ratios. Raemy and Hager (1997) examined the opening and closing moments at various angles of opening, and Brants (1995) documented the use of such gates in Indonesia. Burt and Styles (1999) observed poorly maintained flap gates in an irrigation project in the Dominican Republic. Medrano and Pitter (1997) and Sweigard and Dudley (1995) worked on prototype flap gates (commonly known as Begemann gates) at the Water Delivery Facility of the Irrigation Training and Research Denter (ITRC) at Cal Poly.

Since 1997, about 40 gates have been installed at the Chowchilla Water District (CWD) of California. The construction of the first CWD gates was based on the early Cal Poly prototypes, which were developed with support of the Mid-Pacific Region of the U.S. Bureau of Reclamation. Although many of the CWD gates performed well, some of the controlled water levels were different from those predicted by the early design

${ }^{1}$ Prof. and Chair., Irrig. Training and Res. Ctr., BioResour. and Agric. Engrg. Dept., California Polytechnic State Univ., San Luis Obispo, CA 93407. E-mail: cburt@calpoly.edu

${ }^{2}$ Student, BioResour. and Agric. Engrg. Dept., California Polytechnic State Univ., San Luis Obispo, CA.

${ }^{3}$ Electronic Technician, BioResour. and Agric. Engrg. Dept., California Polytechnic State Univ., San Luis Obispo, CA.

${ }^{4}$ Dir., Irrig. Training and Res. Ctr., BioResour. and Agric. Engrg. Dept., California Polytechnic State Univ., San Luis Obispo, CA. procedure. As a result of the discrepancies, ITRC developed the new design procedure explained in this paper. Gates based on the new design have also been installed in the Turlock Irrigation District (ID), Alta ID, and Broadview WD of California.

\section{PROCEDURES AND METHODS}

\section{Pressure Distribution-General}

The ITRC design program (an EXCEL spreadsheet) estimates the closing and opening couples of the gate at a variety of angles with a desired upstream water level. If one knows the mass and relative locations of all the steel members, the centroid of the mass can be determined from basic statics equations to compute the gate-closing couple.

The opening couple on a flap gate is more complex to com-

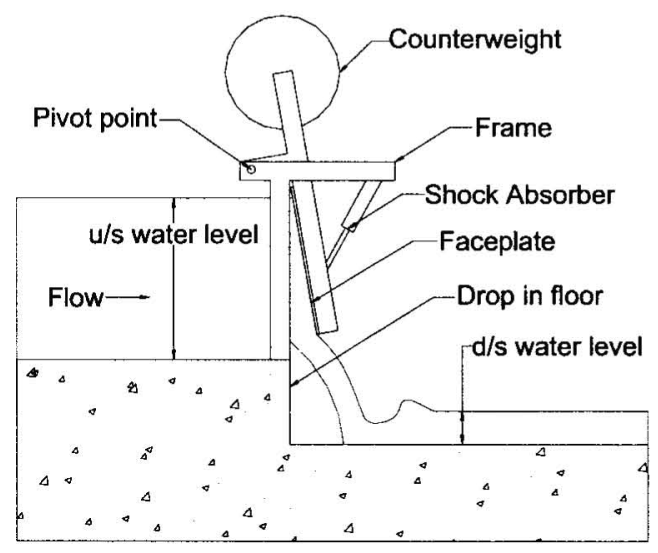

FIG. 1. Side View of Flap Gate

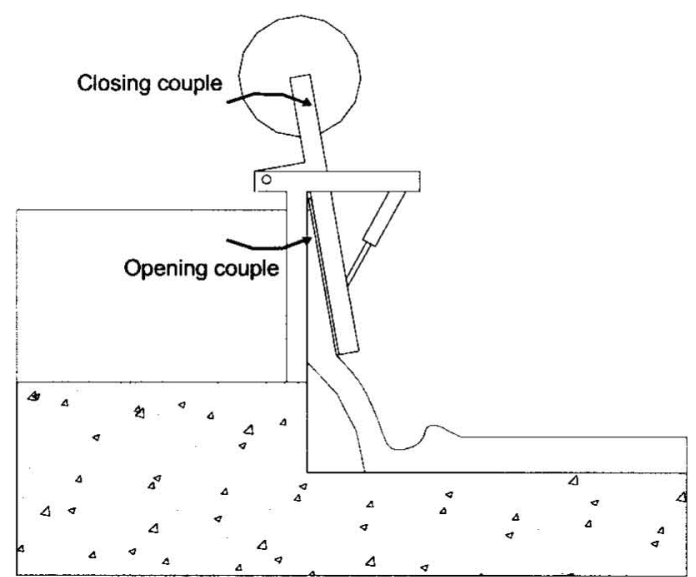

FIG. 2. Balance of Couples on Flap Gate 


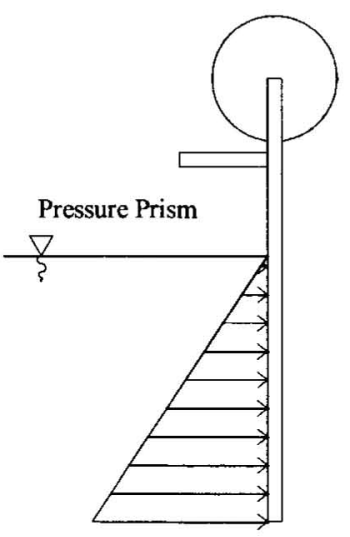

Gate Closed; No Flow

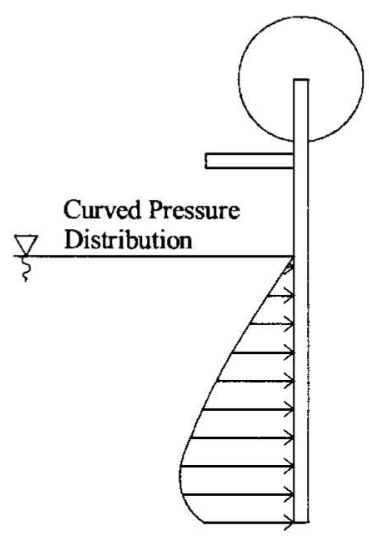

Gate Movement Impending
FIG. 3. Pressure Distribution on Faceplate of Flap Gate; at Slightest Opening, Pressure Distribution Changes from Prism to Curved Shape

TABLE 1. Dimensions of ITRC Water Delivery Facility Prototype Flap Gate

\begin{tabular}{|c|c|c|}
\hline \multirow[b]{2}{*}{$\begin{array}{c}\text { Specifications } \\
\text { (1) }\end{array}$} & \multicolumn{2}{|c|}{ Dimensions } \\
\hline & $\begin{array}{c}\text { English unit } \\
\text { (2) }\end{array}$ & $\begin{array}{l}\text { SI unit } \\
(3)\end{array}$ \\
\hline $\begin{array}{l}\text { U/S water level above bottom of static } \\
\text { frame } \\
\text { Width of structure opening } \\
\text { Height of pivot above bottom of static } \\
\text { frame } \\
\text { Vertical distance from top of water to } \\
\text { top of faceplate } \\
\text { Horizontal level arm } p \\
\text { Static frame tubing dimensions } \\
\text { Faceplate overlap over frame } \\
\text { Faceplate thickness } \\
\text { Dynamic frame tubing dimensions } \\
\text { Density of material in counterweight } \\
\text { Counterweight pipe outside diameter } \\
\text { Counterweight pipe length } \\
\text { Vertical distance of counterweight above } \\
\text { pivot }\end{array}$ & $\begin{array}{l}15.25 \text { in. } \\
36 \text { in. } \\
22.25 \text { in. } \\
4.5 \text { in. } \\
2.75 \text { in. } \\
2 \times 2 \text { in. } \\
0.25 \text { in. } \\
0.19 \text { in. } \\
2 \times 2 \text { in. } \\
152 \mathrm{lb} / \text { cu. } \mathrm{ft} \\
12.75 \text { in. } \\
21 \mathrm{in} . \\
10.5 \text { in. }\end{array}$ & $\begin{array}{l}38.7 \mathrm{~cm} \\
19 \mathrm{~cm} \\
56.5 \mathrm{~cm} \\
11.4 \mathrm{~cm} \\
7 \mathrm{~cm} \\
5.1 \times 5.1 \mathrm{~cm} \\
0.6 \mathrm{~cm} \\
0.5 \mathrm{~cm} \\
5.1 \times 5.1 \mathrm{~cm} \\
32.4 \mathrm{~cm} \\
53.3 \mathrm{~cm} \\
\\
26.7 \mathrm{~cm}\end{array}$ \\
\hline
\end{tabular}

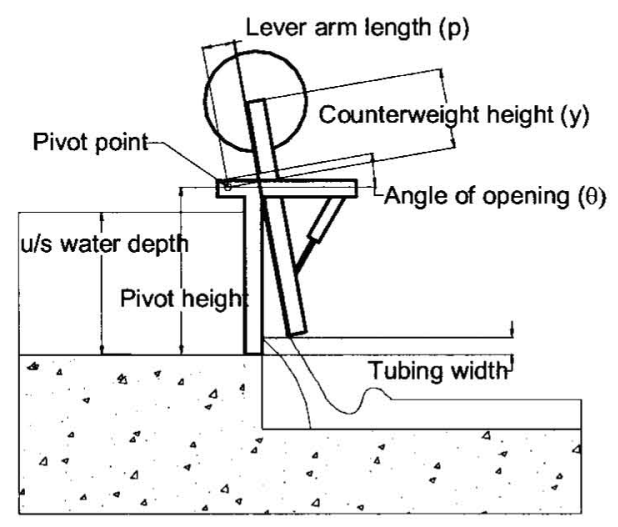

FIG. 4. Dimensions of Flap Gate, Side View

pute. Hydraulic evaluations on flap gates were conducted by Raemy and Hager (1997) to examine the pressure distribution pattern on a flap gate. They determined that the gate could only be assumed to have a linear pressure distribution at zero flow. The difference between static force and actual force increased as the gate opened. This reduction in force was due to the fact that the water exiting the bottom of the gate had a pressure of zero (atmospheric), as seen in Fig. 3.

A prototype flap gate at the ITRC Water Delivery Facility was used to determine the pressure distributions at a variety

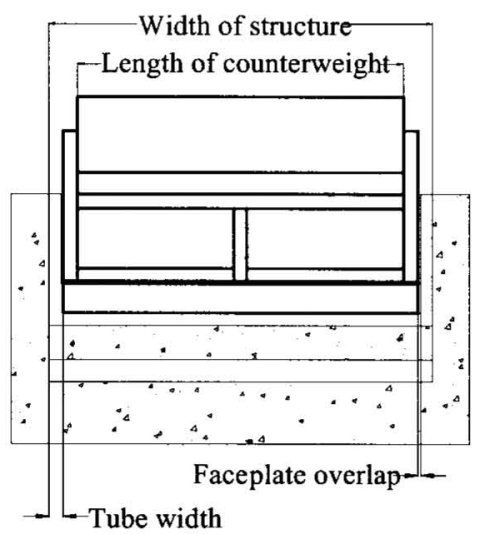

FIG. 5. Dimensions of ITRC Flap Gate, Front View

of flows, gate openings, and water levels. The dimensions of the first ITRC flap gate are shown in Table 1. Figs. 4 and 5 provide schematics of the various dimensions with the labels used throughout this paper and the design spreadsheet.

Thirty-two (32) holes were drilled in the faceplate of the ITRC prototype flap gate, 4 holes per column with 8 columns. The holes were evenly spaced, with each one placed in the center of an area of $95 \times 100 \mathrm{~cm}$. Clear tubes were connected to the holes, and the total dynamic pressure heads (velocity head plus static head) were measured at various flow rates, upstream depths, and angles of opening.

Fig. 6 shows the total dynamic head (pressure) distribution for a condition of 2,350 gal./min (148 L/s). Each curve in Fig. 6 represents the pressures from a different column of holes. There is a slight variation in the magnitude of the pressure between the center of the gate and the edges. This decrease is due to water exiting along the sides of the face plate of the gate. Similar data were measured for two other flow rates (259 and $322 \mathrm{~L} / \mathrm{s}$ ).

The average pressure distribution curves for each of the three flow rates are shown in Fig. 7. The plotting axis of the pressures and the hole locations were switched to obtain a vertical orientation of the curves, allowing a parabolic curve fit for analysis.

\section{Force Calculations}

As the flow rate increases, the opening angle increases while the hydraulic forces on the gate decrease. Not only is each total hydraulic force different, but the location of the centroid of each resulting force on the faceplate is also different. Both of these components need to be determined so that the opening moment (couple) can be calculated.

The area under the parabolas can be determined by integrating the equations shown in Fig. 7. The integration of the 2,350 gal./min $(148 \mathrm{~L} / \mathrm{s})$ equation is as follows:

$$
A=\int y d x
$$

Area for $2,350 \mathrm{gal} . / \mathrm{min}$

$$
=\int_{0}^{346}-0.0032 x^{2}+0.4843 x+183.58 d x
$$

where $346=$ water height above the bottom on the faceplate in millimeters. By averaging the curve data points to obtain a best fit curve for integration, there are some slight errors in the force of the water surface, but these have a minimal effect on the final answer

$$
\text { Area for } 2,350 \mathrm{gal} . / \mathrm{min}=48,325 \mathrm{~mm}^{2}
$$




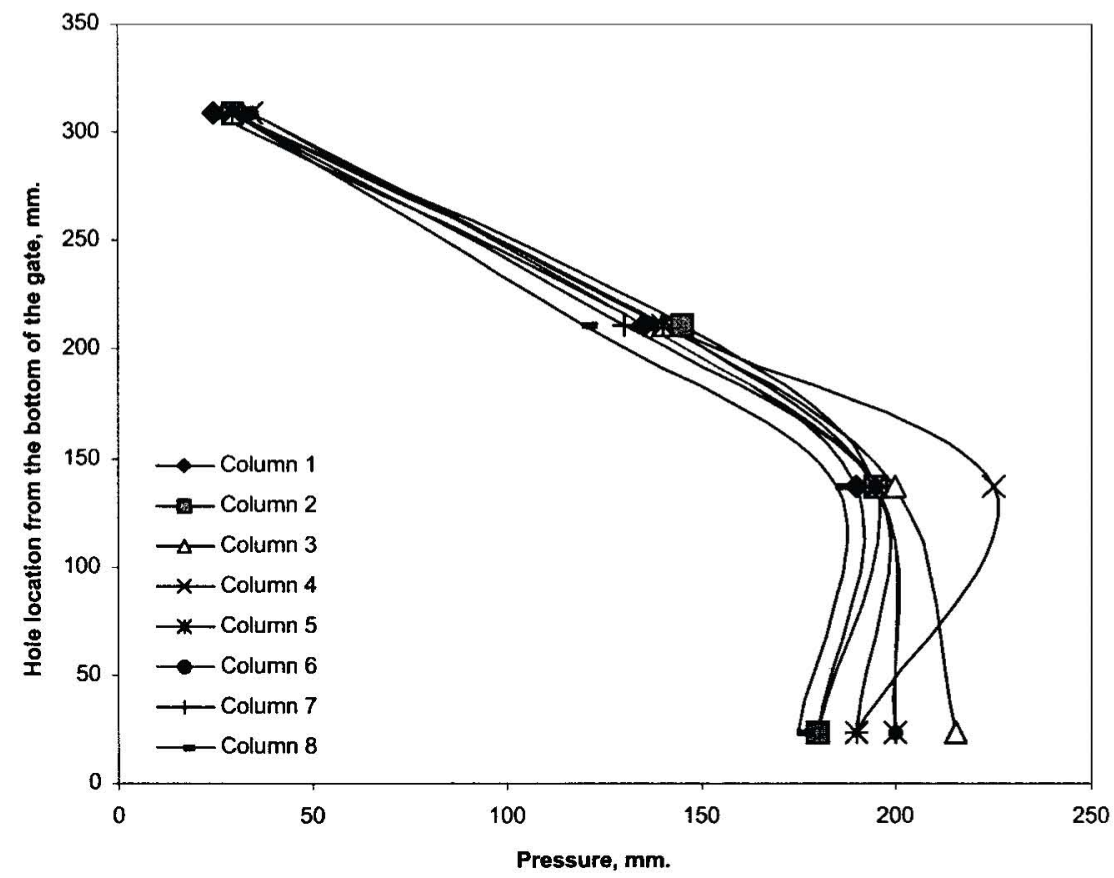

FIG. 6. Pressure Distribution on Faceplate: Flow Rate $=\mathbf{2 , 3 5 0}$ gal./min (148 L/s); Controlled Water Level $=346 \mathrm{~mm}$, Gate Angle $=9.04^{\circ}$

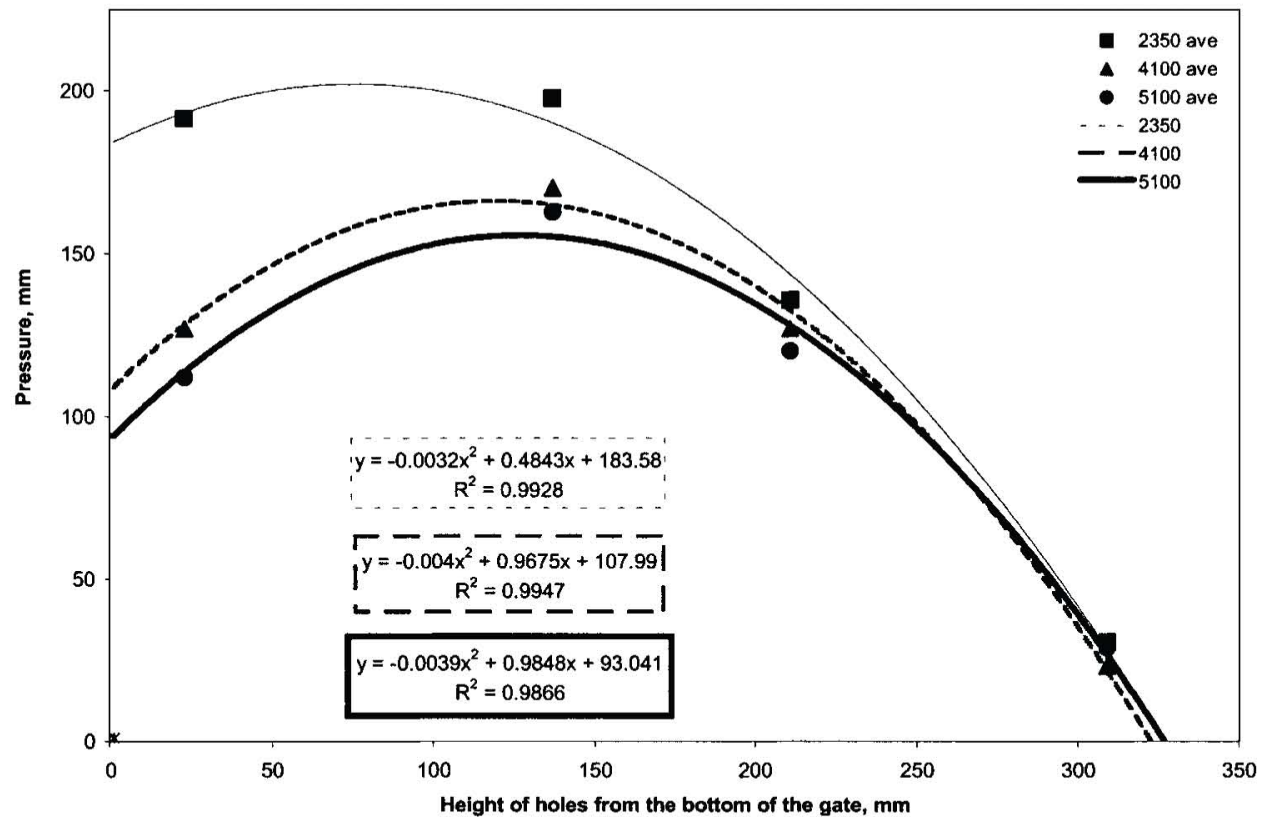

FIG. 7. Averaged Pressure Curves with Parabolic Fit

TABLE 2. Opening Forces versus Flow Rate and Gate Opening Angle-Prototype ITRC Gate

\begin{tabular}{c|c|c}
\hline \hline $\begin{array}{c}\text { Flow } \\
\text { [gal./min (L/s)] }\end{array}$ & $\begin{array}{c}\text { Angle of opening } \\
\text { (degrees) } \\
(1)\end{array}$ & $\begin{array}{c}\text { Force } \\
(\mathrm{N})\end{array}$ \\
\hline 0 & 0 & $(3)$ \\
$2,350(148)$ & 9.0 & 466 \\
$4,100(259)$ & 13.1 & 385 \\
$5,100(322)$ & 16.8 & 318 \\
\hline
\end{tabular}

The areas for the 4,100 and 5,100 gal./min flow curves are 39,890 and $36,657 \mathrm{~mm}^{2}$, respectively.

The forces can be calculated from these areas by multiplying by the width of the gate, the density of water, and gravitational acceleration. The width of the prototype ITRC flap
TABLE 3. Adjusted Forces and Adjustment Factors

\begin{tabular}{c|c|c}
\hline \hline $\begin{array}{c}\text { U/S water } \\
\text { level } \\
(\mathrm{mm})\end{array}$ & $\begin{array}{c}\text { Adjustment } \\
\text { factors }\end{array}$ & $\begin{array}{c}\text { Adjusted force } \\
\text { values } \\
(\mathrm{N})\end{array}$ \\
\hline 342 & $(2)$ & $(3)$ \\
346 & 1 & 466 \\
350 & 0.99 & 381 \\
360 & 0.98 & 311 \\
\hline
\end{tabular}

gate was $813 \mathrm{~mm}$. The flow rates with corresponding forces can be seen in Table 2 .

The ITRC gate did not maintain a precise constant water level. The forces were adjusted by taking the target water depth and dividing it by the actual water depth at each flow 


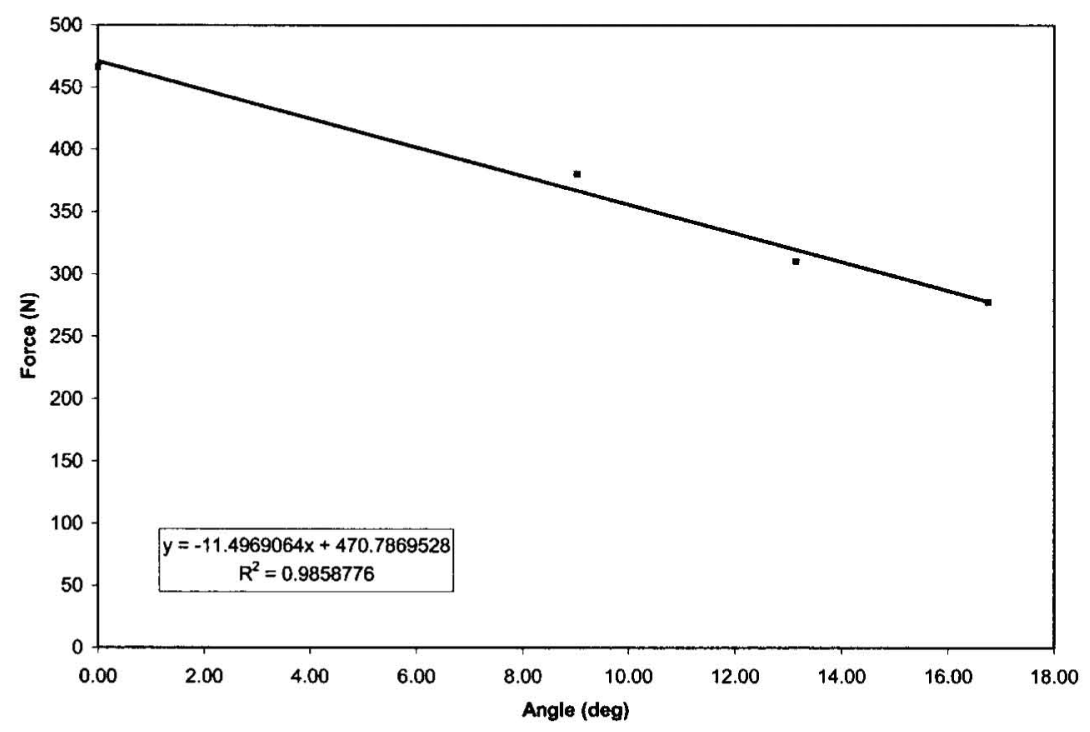

FIG. 8. Adjusted Force versus Angle of Opening for ITRC Prototype Flap Gate

to obtain an adjustment factor. Then each force was multiplied by its corresponding adjustment factor to determine what the force would have been had the water level remained constant. These adjustment factors and the adjusted forces can be seen in Table 3.

Fig. 8 shows the relationship between the adjusted force and the angle of gate opening, specifically for the gate at the ITRC. The slope should be the same for any similar gate, whereas the intercept (force when closed) is specific to each gate. To make a universal equation for all gates, a "force ratio" was developed as:

Force ratio $=\frac{\text { slope }}{\text { ITRC gate force at zero flow }}$

$$
=\frac{-11.50}{470.78}=-0.024
$$

With this force ratio the actual force on the gate can be calculated at any angle by knowing the static force on the gate

Force $(N)=($ force at zero flow rate $)(1+($ force ratio $) \cdot \theta)$

$$
\text { Force }(\mathrm{N})=\left(\gamma \frac{h_{s}}{2} A\right)(1-0.024 \cdot \theta)
$$

where $\gamma=$ specific weight of water $\left(9,807 \mathrm{~N} / \mathrm{m}^{3}\right) ; \theta=$ angle of opening (degrees); $h_{s}=$ upstream water depth, measured from the bottom of the faceplate $(\mathrm{m})$; and $A=$ area of faceplate $\left(\mathrm{m}^{2}\right)$.

\section{Centroid Calculations}

The vertical location of the centroid of the forces can be found by applying the integral in (7) to the equations found in Fig. 7. This value is needed to calculate the opening moment on the gate

$$
\bar{x}=\frac{\int x y d x}{\text { area }}
$$

For the 2,350 gal./min $(148 \mathrm{~L} / \mathrm{s})$ flow rate

Centroid for 2,350 gal./min

$$
=\frac{\int_{0}^{346} x \cdot\left(-0.0032 x^{2}+0.4843 x+183.58\right) d x}{\text { area for } 2,350 \text { gal./min }}
$$

Centroid for 2,350 gal./min

$=126 \mathrm{~mm}$ (from the bottom of the faceplate)

The centroids for the 4,100 gal./min $(259 \mathrm{~L} / \mathrm{s})$ and 5,100 gal./min (322 L/s) flows are 130 and $132 \mathrm{~mm}$, respectively, from the bottom of the faceplate. The values of the three centroid locations were plotted against the opening angle. A bestfit line was plotted on the data points, and an equation was obtained (Fig. 9).

A centroid location ratio similar to the force ratio was developed by dividing the slope by the $y$-intercept (pressure prism centroid). This enables the centroid location to be determined for any gate, at any angle

Centroid location ratio $=\frac{\text { slope }}{y \text {-intercept }}=\frac{0.0011}{0.1174}=0.00919$

With this ratio the location of the resultant force (centroid) can be calculated for any angle of opening by knowing the static water level height

$$
h_{c}=\left(\frac{h_{s}}{3}\right)(1+0.009 \cdot \theta)
$$

where $h_{s}=$ upstream static water level, measured from the bottom of the faceplate $(\mathrm{m})$.

\section{Opening Moment}

Combining the force and location data, the opening moment can be computed for any angle of operation

Opening moment $(\mathrm{N} \cdot \mathrm{m})=\frac{\left(\gamma h_{s} A\right)}{2}(1-0.024 \cdot \theta)$

$$
\cdot\left(L_{p}-\frac{h_{s}}{3}\right) \cdot(1+0.009 \cdot \theta)
$$

where $L_{p}=$ vertical distance from pivot point to the bottom of the faceplate when vertical.

\section{Closing Moment}

A spreadsheet can be used to locate the vertical position of the counterweight so that the moments are most nearly equal at all angles of opening

$$
\text { Closing moment }(\mathrm{N} \cdot \mathrm{m})=(M \cdot g) \cdot\left(P-\left(H_{c g} \cdot \tan (\theta)\right) \cdot \cos (\theta)\right)
$$




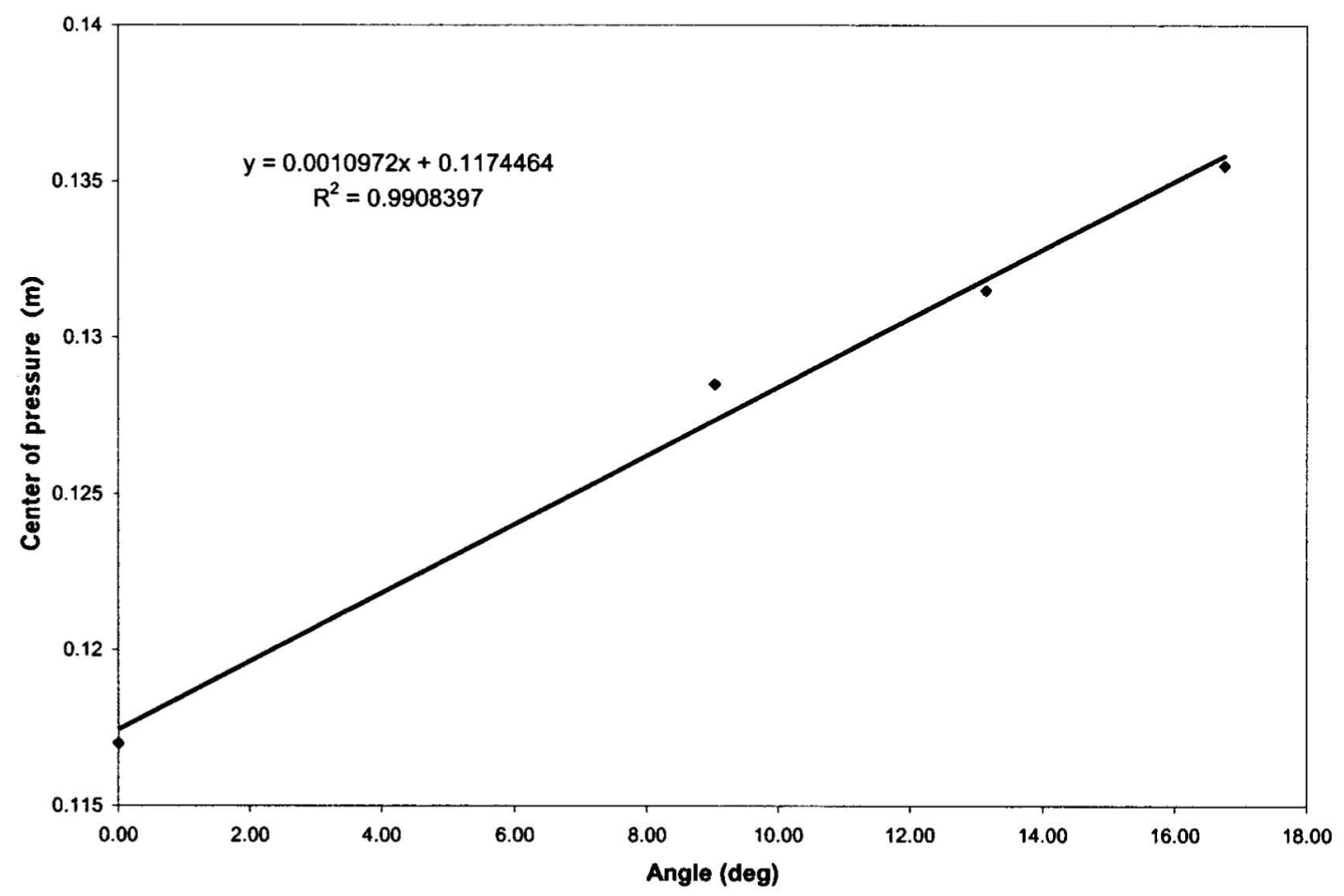

FIG. 9. Angle of Opening versus Pressure Centroid from Faceplate Bottom

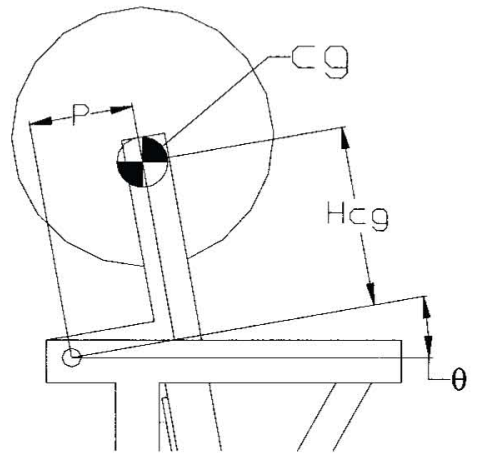

FIG. 10. Closing Moment Lever Arm

where $M=$ mass of the gate and counterweight $(\mathrm{kg}) ; c g=$ center of gravity of the gate; $g=$ gravitational acceleration $\left(9.821 \mathrm{~m} / \mathrm{s}^{2}\right) ; P=$ horizontal distance from the center of the pivot point to the center of gravity of the gate $(\mathrm{cg})(\mathrm{m})$ when closed; $H_{c g}=$ vertical distance from the center of the pivot pin to the $c g(\mathrm{~m})$ when closed (Fig. 10); and $\boldsymbol{\theta}=$ angle of opening (degrees).

\section{Water Level Variation}

The spreadsheet design program computes the closing and opening moments in $2^{\circ}$ increments. It then computes a new opening moment with a slightly higher water level and then with a slightly lower water level. Using this information, regarding the sensitivity of the moment to the upstream water level, the program estimates the change in water level (from the target) that will occur with the difference in closing and opening moments at each angle (Fig. 10). One can adjust various parameters to determine the sensitivity of any gate design. Although the determination of the opening moments is a focus of this paper, the computation of the maximum water level variation is the weakest link in the design procedure.

\section{Maximum Flow Rate}

The maximum flow rate is first approximated using a simple weir equation in which the head $H$ is the depth of water up- stream of the structure. The program then estimates a second flow rate using an orifice equation, using the gate opening at the maximum opening angle (before the center of gravity passes beyond the pivot point). The smaller of the two flow rates is listed in the spreadsheet as the maximum flow rate.

\section{EXCEL SPREADSHEET PROGRAM}

\section{Program Description}

The spreadsheet has 12 user-input locations that request 17 values ranging from the desired upstream water level to the density of material used in the counterweight (Fig. 11). Most units are English to facilitate easy usage by irrigation district personnel in California, Oregon, and Nevada. Table 4 shows an example of the final dimensions provided by the spreadsheet.

In some cases the design will have considerable cross bracing and other material weights that will impact the closing couple. One can sometimes approximate the impact of increased weight by adjusting the value that is input for the faceplate thickness.

The spreadsheet program highlights key ratios and values in yellow or purple. These values are as follows:

1. The weight of the counterweight must be adjusted until the opening and closing moments are equal at zero flow. Although this tends to overestimate the counterweight in some cases, it appears to be the best procedure for estimating the quality of water level control.

2. The ratio of "distance from the water surface to the pivot point" versus "water depth above the bottom static frame" should be $<0.5$. This ratio limit was identified by Brouwer (1987) and matches observations by the ITRC using the design program and from the field.

3. The horizontal distance between the pivot and the upstream of the faceplate should be relatively small $(<25 \%)$ compared to the height of the pivot above the bottom of the gate opening.

4. The center of gravity of the gate (not to be confused with 


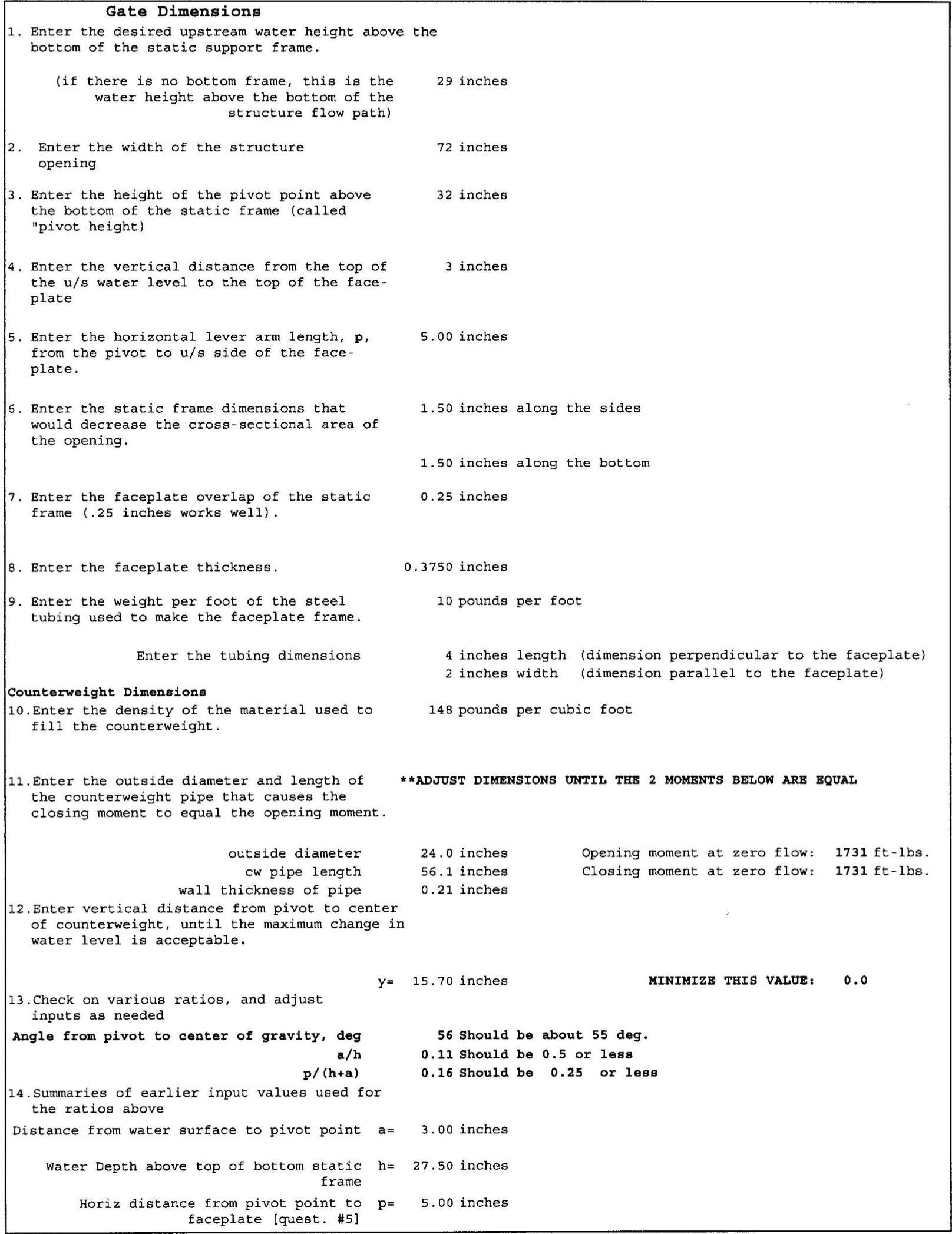

\section{FIG. 11. Example Design EXCEL Program Input}

the counterweight only) should be located at about $55^{\circ}$ vertically above the pivot point.

\section{Program Testing}

Gates that were previously designed and installed in the CWD were used to verify the new design program. Dimensions and notes on some of the CWD gates were collected by the ITRC and Doug Welch, the CWD manager. The results paralleled the recommendations provided by the new design program.

\section{DISCUSSION}

It is impossible to obtain a design that provides an exact match of moments (couples) at all angles of opening, but they 
TABLE 4. Final Dimensions of Example Gate Design

\begin{tabular}{|c|c|}
\hline $\begin{array}{c}\text { Specifications } \\
\text { (1) }\end{array}$ & $\begin{array}{c}\text { Dimensions } \\
(2)\end{array}$ \\
\hline $\begin{array}{l}\text { Pivot height above bottom of static } \\
\text { frame } \\
\text { Lever arm length } p \\
\text { Counterweight height } y \\
\text { Minimum pivot shaft diameter } \\
\text { Steel gate faceplate } \\
\text { Steel pipe } \\
\text { Total length of square tubing (not } \\
\text { cw pipe) used for pivoting parts } \\
\text { Mass of gate without counter- } \\
\text { weight } \\
\text { Mass of counterweight } \\
\text { Total mass } \\
\text { Maximum angle of opening } \\
\text { Estimated maximum flow rate }\end{array}$ & $\begin{array}{l}32 \mathrm{in} . \\
5.00 \mathrm{in} . \\
15.70 \mathrm{in} . \\
2.29 \mathrm{in} . \\
30.75 \mathrm{in} . \text { high } \times 69.50 \mathrm{in} . \text { wide } \\
24.00 \mathrm{in} . \text { diameter } 56.05 \mathrm{in} . \text { long } \\
21.60 \mathrm{ft} \text { (not including static frame) } \\
548 \mathrm{lb} \\
2,401 \mathrm{lb} \\
2,948 \mathrm{lb} \\
26^{\circ} \text { (put the stop before this) } \\
43 \mathrm{cfs}\end{array}$ \\
\hline
\end{tabular}

TABLE 5. Opening and Closing Moments for Example Design

\begin{tabular}{c|c|c|c|c}
\hline \hline $\begin{array}{c}\text { Angle } \\
\text { (degrees) } \\
(1)\end{array}$ & $\begin{array}{c}\text { Opening } \\
\text { moment } \\
(\mathrm{ft}-\mathrm{lb}) \\
(2)\end{array}$ & $\begin{array}{c}\text { Closing } \\
\text { moment } \\
(\mathrm{ft}-\mathrm{lb}) \\
(3)\end{array}$ & $\begin{array}{c}\text { Change in } \\
\text { moment } \\
(\mathrm{ft}-\mathrm{lb}) \\
(4)\end{array}$ & $\begin{array}{c}\text { Change in } \\
\text { water level } \\
(5)\end{array}$ \\
\hline 0 & 1,731 & 1,731 & 1 & 0.0 \\
2 & 1,619 & 1,640 & -22 & -0.2 \\
4 & 1,509 & 1,548 & -39 & -0.5 \\
6 & 1,402 & 1,453 & -51 & -0.6 \\
8 & 1,298 & 1,357 & -59 & -0.8 \\
10 & 1,197 & 1,259 & -62 & -0.9 \\
12 & 1,100 & 1,160 & -60 & -1.0 \\
14 & 1,005 & 1,059 & -54 & -1.0 \\
16 & 913 & 957 & -44 & -0.9 \\
18 & 824 & 854 & -30 & -0.6 \\
20 & 738 & 750 & -11 & -0.3 \\
\hline \hline
\end{tabular}

can be very similar (Table 5). Furthermore, the spreadsheet uses the angle/pressure relationship for the ITRC gate, and that relationship will be somewhat different for other level arm and height combinations. For those reasons, the spreadsheet only provides a relative number (derived from the water level variation computations) that should be minimized during design.

Another consideration when designing a flap gate is the depth of water the gate controls. The size of the counterweight increases dramatically as the depth of water on the faceplate increases.

\section{OTHER DESIGN CONSIDERATIONS}

\section{Strength of Structure}

The spreadsheet provides no analysis of the structural soundness of a gate or of the supporting structure. Such an analysis is essential for each installation due to the large counterweights that can be required with this gate design.

\section{Velocity Head and Skimming}

The flap gate has been observed to work best in conditions that always maintain orifice flow and that have a relatively low approach velocity head. In a channel with a peak velocity of close to $5 \mathrm{ft} / \mathrm{s}(1.5 \mathrm{~m} / \mathrm{s})$, it was noticed that the gate maintained a fairly constant water level immediately upstream of itself. However, about $50 \mathrm{~m}$ upstream, the water level appeared to rise by a depth approximately equivalent to the velocity head at high flow rates due to the different cross section of the canal.

Also, the gate has not worked well if it is positioned with a gap between the bottom of the faceplate and submerged flashboards.

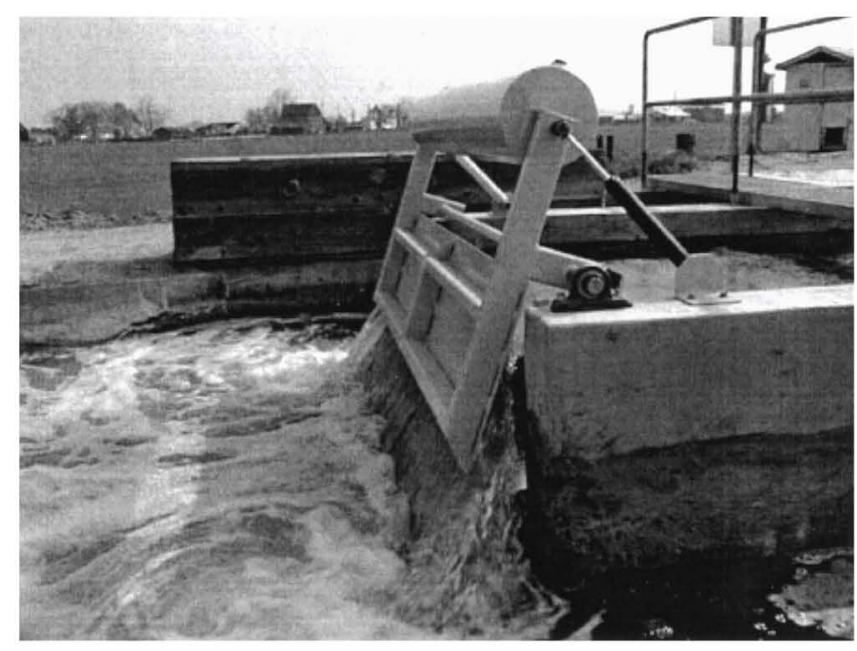

FIG. 12. Flap Gate at Turlock ID, Calif.; This Gate Was Designed without Frame, and Has a Stabilizer in Different Position Than That Shown in Fig. 1

\section{Pivot Limits}

Stops must be installed on the gate to prevent the gate from opening too far, which will cause the center of gravity to move beyond the pivot point, at which point the gate flips over backward with possible catastrophic consequences. The program outputs a value for the maximum angle of opening, which is the angle at which the center of gravity is directly above the pivot point. Stops should be installed to prevent gate movement a few degrees before this maximum value.

\section{Dampening}

Shock absorbers must be installed on the gate to dampen any oscillations that will be caused by wave action. This is essential. Steering stabilizers for semitrucks have also been reported to work well by the Turlock ID staff (Fig. 12).

\section{Installation Notes}

Although the spreadsheet program can assist an engineer to design a gate with precise dimensions, the way the gate is built and installed will affect its hydraulic performance. There are numerous configurations of sidewalls and floors that will give somewhat different hydraulic forces on the flap gate. For this reason not all of the required counterweight mass should be on the gate when it is first installed. After observing the gate's operation, field adjustments can be made to provide the desired accuracy. It is recommended that the concrete for the counterweight be poured on-site, making the handling of the gate much easier. Also, when pouring concrete, some room should be left in the counterweight pipe for final "tuning" with lead buckshot, for example.

\section{SUMMARY}

Flap gates provide a simple and cost-effective mechanism to maintain upstream water levels in small canals. Once installed and proper operation is verified, the gate only requires lubrication of its bearings and occasional painting for maintenance. It needs no electric power and no manual adjustment for varying flow rates.

The design spreadsheet described in this paper allows a designer to size a gate so that in general the final installed gate may only need a minor counterweight mass adjustment. The design program is available as a report on the ITRC web page at 〈www.itrc.org $\rangle$.

Depending on the size and design of the gate, water level 
control $<1$ in. $(2.5 \mathrm{~cm})$ has been obtained. For this reason, and due to the low maintenance and initial costs, the flap gate is a prime candidate to replace existing flashboards if there is sufficient head to avoid downstream submergence. In the field, there are wide variations in hydraulic conditions and there is imprecise knowledge of the moments on the gates at all angles and conditions. Therefore, the design program should be used as guidance rather than as a source of extremely precise values.

\section{ACKNOWLEDGMENTS}

Funding for this research was provided by a grant from the Water Conservation Office of the Mid-Pacific Region of the U.S. Bureau of Reclamation, Dept. of Interior. Doug Welch of the CWD provided considerable insight and cooperation for this project.

\section{APPENDIX I. REFERENCES}

Brants, M. L. A. (1995). "Automatic gates facilitate water management in Punggur Utara Irrigation Project (Indonesia)." Rep., Haskoning Royal Dutch Consulting Engineers and Architects, Nijmegen, The Netherlands.

Brouwer, R. (1987). "Design and application of automatic check gate for tertiary turnouts." Proc., 13th Congr. of ICID, Rabat. International Commission on Irrigation and Drainage, Rabat, Morocco, 671-683.

Burt, C. M., and Styles, S. W. (1999). "Modern water control and management practices in irrigation. Impact on performance." Water Rep. No. 19, Food and Agriculture Organization of the United Nations, Rome.

Medrano, B., and Pitter, M. (1997). "Design, construction, installation and evaluation of a Begemann canal check gate for Chowchilla Water District." Sr. Proj., Agric. Engrg. Dept., California Polytechnic State University, San Luis Obispo, Calif.
Raemy, F., and Hager, W. (1997). "Flap gate for hydraulic head control." Proc., 27th Congr. of the Int. Assn. for Hydr. Res., ASCE, Reston, Va., $320-325$.

Sweigard, J., and Dudley, K. (1995). "Design, construction, installation and evaluation of a Begemann counter-weight upstream control gate." Sr. Proj. Agric. Engrg. Dept., California Polytechnic State University, San Luis Obispo, Calif.

Vlugter, H. (1940). "Over zelfwerkende peilregelaars bij den Waterstaat in Nederlandsch-Indië." De Ingenier in Ned.-Indië., No. 6, 11.8411.93 .

\section{APPENDIX II. NOTATION}

The following symbols are used in this paper:

$A=$ area of face plate $\left(\mathrm{m}^{2}\right)$;

$c g=$ center of gravity of gate;

$g=$ gravitation acceleration $\left(9.821 \mathrm{~m} / \mathrm{s}^{2}\right)$;

$h=$ upstream water level (ft);

$h_{c}=$ vertical depth of centroid;

$H_{c g}=$ vertical distance from center of pivot pin to $c g(\mathrm{~m})$;

$h_{s}=$ upstream static water level, measured from bottom of faceplate $(\mathrm{m})$;

$L=$ width of opening $(\mathrm{ft})$;

$L_{p}=$ vertical distance from pivot point to bottom of faceplate when faceplate is vertical $(\mathrm{m})$;

$M=$ mass of gate and counterweight $(\mathrm{kg})$;

$P=$ horizontal distance from center of pivot pin to center of gravity of gate $(\mathrm{cg})(\mathrm{m})$;

$Q=$ flow rate $(\mathrm{cfs})$

$\bar{x}=$ vertical location of centroid of force areas;

$\gamma=$ specific weight of water $\left(9,807 \mathrm{~N} / \mathrm{m}^{3}\right)$; and

$\theta=$ angle of opening (degrees). 